\title{
A política de Constantino e a formação do Império Romano do Orientel
}

Cláudio Umpierre Carlan*

Resumo: o artigo começa com uma descrição do mundo romano após a Tetrarquia, com a luta pelo poder entre Constantino e, mais tarde, Licínio. Analisamos as questões políticas relativas ao mundo romano durante o período. Enfatiza-se, nessa discussão, a importância do uso de uma variedade de fontes: iconográficas, arqueológicas e textuais. Usando como fonte iconográfica a coleção numismática do acervo do Museu Histórico Nacional / RJ, empregamos a imagem como uma fonte de propaganda, legitimando o poder imperial.

Palavras-chave: Moeda. Império. Iconografia. Poder. Símbolo.

\section{Introdução}

Para a maioria dos pesquisadores, durante o período conhecido como Baixo Império ou Antiguidade Tardia (séculos III e V), o Império Romano presenciou uma crise sem fim na sua estrutura política, social, econômica e administrativa.

Roma teve de lidar com uma série de migrações e invasões dos povos germânicos, conhecidos pejorativamente como "bárbaros".

\footnotetext{
* Doutor em História Cultural (Antiga) pela UNICAMP. Professor-Adjunto de História Antiga / Universidade Federal de Alfenas (UNIFAL / MG). Pesquisadorassociado ao Grupo de Pesquisa Arqueologia História da UNICAMP. Email: claudiocarlan@yahoo.com.br
}

Anos 90, Porto Alegre, v. 16, n. 30, p. 61-75, dez. 2009 
Até os dias atuais termos como bárbaros e vândalos, por exemplo, estão associados à destruição e massacres. As definições greco-romanas de bárbaro - aquele que não falava o latim ou grego, vivia fora das fronteiras do Império, usava calças - estão há muito esquecidas. A própria origem do termo vandalismo está associada aos povos Vândalos, germânicos que saquearam e incendiaram Roma no início do século V.

Enquanto o Ocidente lutava para sobreviver, o Oriente sofria menos com esses ataques, estava em uma situação mais estável.

$\mathrm{Na}$ realidade, a parte Ocidental do Império conseguiu um período de estabilidade durante os vinte anos da Tetrarquia (285-305), na qual uma série de reformas foram implantadas, graças à energia dos Imperadores Ilíricos, grupo de governantes originários da Ilíria (atual Europa Oriental, perto da Albânia). Na tentativa de resolver os problemas socioeconômicos criados durante a Anarquia Militar, eles tentaram realizar uma série de reformas. ${ }^{2}$ Esses governantes e seus soldados eram federados de Roma, comandados pelos seus líderes e não oficiais romanos. Lograram restaurar o poder, conter os persas sassânidas e outros invasores germânicos.

Anos mais tarde, Constantino I (272 - 337), o grande, reestabelece a unidade imperial, se autoproclamando herdeiro da Tetrarquia, sistema político de que seu pai, Constâncio I ou Constâncio Cloro (Claro em latim), fez parte. Sua dinastia, que governa até o ano de 363, conseguirá manter Roma unida e estável. O maior exemplo disso é a ideia dinástica apresentada no século IV, onde conhecemos uma dinastia constantiniana, valentiniana e teodosiana, todas ligadas entre si através do laço de parentesco.

A ideia familiar foi suficientemente forte para que, de uma dinastia a outra, se procurasse criar um laço através do matrimônio. Valentiniano casa o filho, Graciano, então com dezesseis anos, com a neta de Constantino, de treze anos. E Teodósio, por sua vez, desposou a filha de Valentiniano.

Começa a surgir um sentimento de lealdade monárquica, apesar de uma série de transtornos. A melhor prova disso é que, apesar de toda a carência militar e política, os filhos de Teodósio I morreram de morte natural. 
Outro fato relevante é que as várias tentativas de usurpação foram derrotadas e o poder restabelecido, retornando às mãos dos "legítimos donos".

Porém, havia um agravante - a capital, Roma, estava em franca decadência. O Senado era imprevisível, sendo comuns a venda da lealdade e a mudança de partido. Do mesmo modo que a elite senatorial apoiava Maxêncio, filho de Maximiano, outro antigo membro da Tetrarquia passou a apoiar a Constantino, quando o seu exército se aproximava dos portões da capital. É bem verdade que a taxação de impostos promovida por Maxêncio ajudou nessa decisão, mas os senadores já flertavam com Constantino havia alguns anos.

Diocleciano, em 285, transferiu a capital administrativa criando dois blocos distintos: Sírmino e Nicomédia no Oriente, Aquiléia e Trèveres (Trier) no Ocidente. A ideia de uma nova capital já estava presente nas discussões políticas desde a segunda metade do século III.

Não foi nenhuma surpresa quando Constantino, em 324, ordenou a construção de uma nova sede administrativa, ao lado do Estreito do Bósforo. Em um primeiro momento, a escolha recaiu sobre a antiga Tróia, porém, por razões estratégicas e comerciais, a cidade escolhida foi a colônia fundada pelos gregos de Mégara em 657 a. C., Bizâncio. Ao longo da sua história, a futura Constantinopla (hoje Istambul) serviu de entreposto comercial entre o Oriente e o Ocidente.

\section{A Política Romana no século IV: o Edito de Milão}

Depois da morte de Galério, em 311, quatro imperadores disputam o poder: Constantino, Maximino Daia, Maxêncio e Licínio. A guerra entre eles torna-se inevitável. Licínio e Maximino se enfrentavam no Oriente e Constantino e Maxêncio, no Ocidente. Em um primeiro momento, Licínio e Maximino fizeram um acordo. Em 313, Licínio casa-se com a meia-irmã de Constantino, Flávia Júlia Constantina, com quem teve um filho, Licínio II. Por razões políticas, volta-se contra Maximino Daia, derrotando-o no mesmo ano. Maximino é condenado à morte e o Oriente volta a ter um único senhor. 
Com a derrota e morte de Maxêncio em 312, na ponte Mílvia, uma nova aliança é estabelecida entre Constantino e Licínio. Após alguns enfrentamentos iniciais, firmaram a paz em Sérdica, no ano de 317. Durante esse período, ambos nomearam novos césares, segundo as suas conveniências, membros de suas famílias, independentemente da idade.

No ano de 313, em Milão, Constantino e Licínio assinam o Edito que declarava a neutralidade religiosa do Império Romano, acabando oficialmente com toda a série de perseguições. A aplicação do Edito foi simples: devolveu aos cristãos os lugares de culto e as pro-priedades que tinham sido confiscadas e vendidas em praça pública e deu ao Cristianismo e às demais religiões um estatuto de legitimidade comparável com o do paganismo, desestabelecendo este como a religião oficial.

$\mathrm{Na}$ tentativa de consolidar o seu domínio, Licínio arma suas legiões contra Constantino I. Como parte do seu esforço de ganhar a lealdade dos soldados, Licínio expulsa os cristãos de suas tropas. Alguns tiveram suas propriedades confiscadas e foram condenados à morte. Segundo Eusébio de Cesaréia, Licínio torna-se um perseguidor.

Depois dos enfrentamentos iniciais, Constantino reunifica o Império em 324. Derrota e manda executar Licínio e o filho deste, Licínio II, em 325, depois de prometer publicamente não fazê-lo. Eusébio de Cesaréia, biógrafo oficial e amigo do imperador, cita em seus escritos que Licínio estava à frente de uma série de intrigas.

A obra religiosa de Constantino é de fundamental importância, pois levou ao estabelecimento de um Império Cristão. A tradição cristã diz que, pouco antes de entrar em combate contra Maxêncio (na Ponte Mívia), o imperador "rezava e fazia frequentes súplicas"; segundo Eusébio de Cesaréia (EUSEBIUS PAMPHILI, 1902, p. 21), surge um sinal divino no céu: as iniciais da palavra Cristo em grego (XPTO), acompanhada da inscrição hoc signus vinces (com esse sinal vencerás). Constantino teria mandado pintar o sinal nos escudos dos soldados, vencendo assim a batalha. Segundo o retórico cristão Lactâncio (LACTÂNCIO, 1954, p. 126), contemporâneo de Eusébio de Cesaréia, a visão de Constantino ocorreu durante o sono, pouco antes do combate. Lembramos ainda que Eusébio escreveu a sua obra em grego e Lactâncio em latim. 
O novo imperador mandou cunhar uma série de moedas que lembravam este fato. Outros governantes, séculos mais tarde, "copiaram" o modelo constantiniano cunhando peças com a mesma legenda e iconografia, como, por exemplo, D. Manoel, o venturoso, de Portugal; D. Pedro I e D. Pedro II, do Brasil, entre outros.

De fato, Constantino tinha inicialmente uma religião solar, de tendência monoteísta, culto ao sol ou sol invictus (também representado em suas amoedações). Ele se considerava inspirado por um Deus Único, porém, mal definido, e mantinha as funções de pontifex maximus (chefe sacerdotal ou chefe da religião, a partir de 391 título do Bispo de Roma ou Papa) e mestre do paganismo.

Funari define essa suposta conversão de Constantino como um jogo político. Segundo o autor:

(...) Assim o imperador Constantino concedeu aos cristãos, por meio do chamado Edito de Milão, em 313, liberdade de culto. Em seguida, esse mesmo imperador procurou tirar vantagem e interveio nas questões internas que dividiam os próprios cristãos e convocou um concílio, uma assembleia da qual participavam os principais padres cristãos. Nos Concílios foram discutidas as diretrizes básicas da doutrina cristã. Depois Constantino cuidou pessoalmente para que as determinações do concílio fossem respeitadas, ou seja, passou a ter um controle muito maior dos cristãos e suas ideias. Antes de morrer, o imperador resolveu batizar-se também.” (FUNARI, 2002, p. 131).

No plano econômico, com o intuito de controlar a inflação, Constantino criou uma nova moeda de ouro, solidus, diminuindo o peso do aureus (antiga moeda de ouro). Essa moeda teve a primeira cunhagem em 310 e conseguiu estabilizar rapidamente o sistema monetário. O solidus circulava só entre a elite político-econômica e não entre as classes mais baixas, que continuavam utilizando moedas de bronze, cobre ou prata que, eventualmente, sofriam as devidas desvalorizações.

Em 324, é cunhado o miliarense, de prata, que poderia chegar ao valor de $1 / 12$ do solidus aureus. Quanto à massa em circulação, é constituída por espécies de cobre e bronze, de peso variável. 
Constantino apoderou-se dos tesouros do antigo rival, Licínio, porém, dois anos mais tarde, a maior parte das casas monetárias, fundadas por Diocleciano, era fechada. Em 332, graças ao confisco dos bens dos templos pagãos, foi possível reabri-las.

De fato, a política constantiniana de grandes despesas não conseguiu deter a inflação. Um fato importante que gerava o aumento dos preços era a prática do fornecimento do pão que, a princípio, era gratuito, passando, em seguida, a um preço reduzido, bem como as distribuições de azeite e de carne de porco, que aumentaram à medida em que foram ampliadas as fronteiras imperiais.

Em 321, o Imperador assina o Edito de Constantino, determinando o domingo como "dia de repouso", exceto para os camponeses. Sobre isso, o Código de Justiniano nos dá uma explicação plausível: nenhum outro dia era mais adequado ao plantio que o domingo (dia do Sol, segundo o código), além de haver a necessidade de se aproveitar o clima e o tempo favorável, dádivas divinas. ${ }^{3}$

$\mathrm{Na}$ administração, ocorreram alterações significativas. $\mathrm{O}$ ministro do tesouro real, o rationalis, cedeu lugar ao conde das liberalidades sagradas, e o procurator rei privatae passou a ser chamado conde dos bens privados, responsável pela organização dos bens e da fortuna do príncipe, para que essas rendas revertessem em ager publicus, dos domínios confiscados, das terras municipais e os recursos dos templos.

Visando reformar o exército, Constantino reduz o número das legiões para mil legionários, dissolve os pretorianos, mantém a logística Diocleciana de taxação em espécie. São criados os guardas imperiais especiais, scholae palatinae.

As tropas romanas atravessaram o Reno e o Danúbio, ao longo de cujos cursos se reconstruiria uma sólida defesa. Tanto que as melhores representações das numárias romanas sobre as fortificações são, respectivamente, as de Constantino, portas de Trèves (Trier) contidas nas moedas de um sólido, e a de seu filho e sucessor, Constâncio II (CARLAN, 2003, p. 22). Da época deste último, há dezessete peças no Museu Histórico Nacional, Rio de Janeiro, que reproduzem a imagem de uma fortaleza ou campo militar. Essas fortalezas teriam de ser solidamente construídas, mas não fortemente defendidas, para evitar a perda de efetivo.

Com a evolução da situação política, fica praticamente impossível para o exército romano manter a ofensiva. Para isso, os impe- 
radores trataram de fortificar as cidades aumentando o número de soldados e reservas de defesa. Mudando a organização interna das legiões, nos períodos anteriores, o aumento de efetivo ocorria apenas durante as campanhas. Durante o século IV, cada vez mais os mer-cenários bárbaros são incorporados ao exército romano (DEPEYROT, 1987, p. 44).

A Mesopotâmia é reconquistada e o Império Sassânida é obrigado a ceder territórios além-Tigre. No Oriente, Roma nunca avançara tão longe. Como exemplo, podemos citar os combates travados entre Constâncio II e Sapor II, nos quais o Imperador Romano obteve os mais variados resultados. Tais combates estão representados nas moedas existentes nos lotes de números 26 e 27 do Museu Histórico Nacional, nas quais aparece a figura de Constâncio, à esquerda de quem observa, de armadura, a cavalo, derrotando um inimigo, que aparece de joelhos, com os braços levantados, como se estivesse suplicando misericórdia. Apesar de a moeda estar um pouco deteriorada, nota-se que a imagem central do imperador romano que é o centro do poder — sempre aparece maior que a do soldado persa. Através da análise desse pequeno objeto de bronze, cujo diâmetro é de 2,5mm, e o peso, de pouco mais de 4 gramas, podemos destacar também a crescente importância da cavalaria, representada aqui como personificação de Constâncio.

A riqueza iconográfica dessa fase é muito bem representada nas medalhas e moedas romanas, ocorrendo uma exaltação à pessoa, na figura do monarca, da própria política real (NIETO SORIA, 1993, p. 17-18), uma espécie de propaganda de comunicação, de que todos os habitantes do vasto Império Romano tomariam conhecimento, através da visualização das peças, legitimando o poder temporal. Isto também explica as várias cidades, espalhadas por todo o território, responsáveis pela cunhagem.

\section{Moedas Comemorativas: a fundação de Constantinopla. ${ }^{4}$}

Dentro de sua política de contenção, Constantino escolheria como nova sede de governo uma cidade próxima às rotas comerciais que ligavam a Europa à Ásia, o mar Mediterrâneo ao mar Negro. 
Outro problema era sobre a questão das fronteiras imperiais. Além do perigo de uma invasão, a pressão política era menor. No século IV, o inimigo fidagal dos romanos era sem dúvida o Império Persa Sassânida, que realizou várias investidas na região.

A nova capital, fundada em 330, batizada de Constantinopla em homenagem ao Imperador, unia as influências orientais, aliadas à arte grega e à organização urbana de Roma.

Em pouco tempo Constantinopla tornou-se a cidade mais cosmopolita do Império. Seus costumes, religião e cultura eram essen-cialmente gregos, porém, consideravam-se romanos. A palavra "grego" estava associada, de maneira injuriosa, ao paganismo. Os persas e, posteriormente, árabes e chineses também associaram os habitantes de Constantinopla a Roma, chamando-os de romanos. O termo bizantino começou a ser utilizado a partir do século XVII, quando os estudiosos o instituíram para fazer uma distinção entre o Império da Antiguidade, Romano do Oriente, e o da Idade Média.

Estrategicamente bem localizada, Constantinopla resistiu a uma série de cercos, provando assim a boa visão militar de Constantino.

Para fortalecer ainda mais a força política da nova capital, o Imperador mandou cunhar uma série de moedas comemorativas, o que ocorreu entre os anos de 330 e 346. Apesar da morte de Constantino em 337 , essas peças continuaram sendo cunhadas, pelos seus herdeiros, até o ano de 341.

\section{Descrição do Corpus}

Esses conjuntos de peças fazem parte do acervo numismático do Museu Histórico Nacional / RJ, que possui o maior espólio de moedas e medalhas da América Latina, com mais de 110 mil exemplares das mais variadas regiões. Desse todo, 414 moedas, sendo 54 moedas comemorativas, foram cunhadas por Constantino ou por sua ordem. $\mathrm{Na}$ legenda que circunda as peças, encontramos o nome e o título imperial. ${ }^{5} \mathrm{Neste}$ artigo analisaremos apenas as moedas referentes à fundação de Constantinopla, deixando as demais peças constantinianas para uma outra oportunidade. Ressaltamos que tanto as moedas como as medalhas são estudadas pela numismática e, no caso 
romano, esses símbolos monetários teriam o papel de passar uma mensagem aos governados, uma espécie de propaganda política / imperial. Florenzano afirma que toda essa riqueza iconográfica, aliada a um trabalho de precisão milimétrico, teria outro objetivo além de uma simples troca comercial (FLORENZANO, 2002, p. 59). Chartier destaca a importância da interpretação desses signos, chamada por ele de "signos do poder".

Daí a necessidade de constituir séries homogêneas desses signos do poder. sejam as insígnias que distinguem o soberano dos outros homens (coroas, ceptros, vestes, selos, etc.), os monumentos que, ao identificarem o rei, identificam também o Estado, até mesmo a nação (as moedas, as armas, as cores), ou os programas que têm por objetivo representar simbolicamente o poder do Estado, como os emblemas, as medalhas, os programas arquitetônicos, os grandes ciclos de pintura.... (CHARTIER, 1990 , p. 220).

Analisando a iconografia, podemos notar toda essa simbologia que demonstra os ritos comemorativos numa transferência do poder instituído pelo governante. Apesar de Constantino ser considerado o primeiro imperador cristão, os ícones pagãos encontram-se expressos nessas peças.

Esse conjunto de objetos foi cunhado a partir do ano de 330, continuando até 346, nove anos após a morte do Imperador (SEAR, 1988, p. 327). Teve como objetivo principal o de legitimar Constantinopla como a nova capital do Império, destinada a rivalizar com Roma, mas não a suplantá-la, como podemos observar em duas cunhagens do período.

Na primeira delas, no anverso notamos o busto da deusa Roma (representando a cidade), voltada à esquerda do observador, com o capacete e o manto imperial, circundada pela legenda VRBS, pois Roma ainda era considerada a Cidade por excelência, aquela que todas as outras deveriam copiar e admirar. No reverso, sem legendas, no campo monetário, a loba amamentando os gêmeos Rômulo e Remo, numa alusão à fundação e origem da cidade. Acima dessas representações, duas estrelas. Algumas moedas vêm acompanhadas de um 
"banho de prata" que, quando conservado, dá um realce artístico muito bonito.

Existem 19 peças com essa simbologia, cunhadas em Roma (6), Constantinopla (5), Siscia (3), Trèves (2), Císico (2), Aquiléia (1).

No outro exemplo, identificamos as seguintes alterações: no an-verso, a representação principal é da cidade de Constantinopla, circundada pela legenda Constantinopolis, seguindo o exemplo da peça ci-tada anteriormente; no reverso, trabalhamos com dois exemplos distintos. No primeiro deles, a imagem da deusa Vitória, uma mulher alada semelhante aos anjos cristãos, à esquerda do observador, sobre a proa de uma embarcação, utilizando como remo uma haste transversal e apoiando-se num escudo. Nesse universo simbólico, a Vitória guia o Império como guia o navio para um "novo porto ou porto se-guro"; escudo é a proteção que a deusa transporta. Não podemos esquecer da importância marítima e estratégica da Nova Capital. No segundo modelo, as alterações ocorrem no reverso - a deusa Ro-ma passa o cetro para a deusa Constantinopla numa nítida troca das funções que circundam o âmbito do poder; o anverso pemanece o mesmo.

Existem 20 moedas com essa iconografia cunhadas nas seguintes cidades: Roma (5), Constantinopla (8), Siscia (1), Aquiléia (1), Antioquia (2), Tessalônica (1), Císico (2), Trèves (1). Além do "banho de prata”, foram identificados alguns quinários, espécie de variação ou desvalorização da prata, muito comum em épocas inflacionárias.

Constantinopla sucedeu à antiga Bizâncio (fundada em 658 a.C.) por vontade de Constantino, que queria dar ao Império uma segunda capital, mais próxima das províncias ameaçadas pelos bárbaros dos Balcãs e pelos persas sassânidas. Construída, ou melhor, reconstruída entre os anos de 324 e 336, a "Nova Roma" foi inaugurada em 11 de maio de 330. Capital política, pela presença do imperador, a partir do final do século IV, religiosa, como sede do patriarcado do Oriente, intelectual, graças à sua "universidade", fundada em 330, econômica, por sua posição na encruzilhada das grandes rotas comerciais, Constantinopla era protegida por um duplo cinturão militar formado pelos "muros" de Constantino (século IV) e de Teodósio (século V), completada, nas três faces marítimas, por importantes fortificações ${ }^{6}$ que a preservaram de todos os assaltos até o século XIII. 


\section{Considerações Finais}

Durante todo o seu reinado, Constantino dedicou-se a reformar profundamente o Império. Modificou a composição do senado, cujo conselho era formado por 600 membros, aumentando-o para 2000 magistrados. Outra inovação foi a reforma da prefeitura do pretório, quando os comandantes da guarda imperial se converteram em altos funcionários provinciais, dotados de amplos poderes civis e responsáveis por manter a ordem pública e as finanças.

Apesar de não retornar à antiga forma de governo de que seu pai fez parte, Constantino limitou-se, dois anos antes de sua morte, a partilhar o governo dos territórios em cinco partes: três, as maiores, seriam entregues a seus filhos; as outras duas, a seus sobrinhos. Ou seja: coube ao filho mais velho, Constantino II, a Bretanha, a Gália e a Espanha; Constâncio II ficou com a rica parte oriental do Império que, desde 333, governava como César em Antioquia; o mais jovem, Constante, ficou com a Itália, a África e a Panônia. Os primos Flávio Júlio, Dalmácio e Anibaliano ficaram, respectivamente, com os Bálcãs e a Ásia Menor.

Com a morte do imperador em 337, teve início um período de lutas internas pelo poder. Os numerosos meio-irmãos e sobrinhos de Constantino foram assassinados por políticos poderosos. Constâncio II defendia uma sucessão dinástica ordenada, livre da disputa entre os diversos ramos da família. Tal ideia, a de assassinar os membros da família, foi defendida por Helena (futura Santa Helena), mãe de Constantino, sendo provável que Constâncio II, o homem-forte do novo regime, tenha ordenado o massacre. Deixou vivos, por razões sucessórias (também como reféns), os jovens primos Constâncio Galo e Juliano. Mais tarde, ambos assumiram a função de César, primeiro Galo, depois Juliano.

Os problemas administrativos e a questão sucessória levam Constâncio a nomear seu primo, Constâncio Galo, como César. A instabilidade de Galo e as intrigas palacianas levam o mesmo a ser executado, sob a acusação de traição. Seu irmão, Juliano, é chamado à presença de Constâncio em Mediolanum (Milão). Em 355, é nomeado César da parte Ocidental do império e casa-se com Helena, irmã de Constâncio. Nos anos seguintes, luta contra as tribos ger-

Anos 90, Porto Alegre, v. 16, n. 30, p. 61-75, dez. 2009 
mânicas que tentavam entrar em território do império. Nesta luta, distingui-se como estrategista, administrador e legislador. Recupera Colonia Agripina (Colônia, Alemanha) em 356, derrotando os alamanos (em Argentoratum, na Batalha de Estrasburgo, França / Alemanha) e assegurando a fronteira do Reno.

Uma nova capital é efetivada, Constantinopla, antiga colônia grega de Bizâncio. A sua vida política, econômica e social, aos poucos vai se fortalecendo, rivalizando com a própria Roma. A ideia de Constantino era enfraquecer o incontrolável senado romano, estabelecendo um eixo político-econômico mais próximo ao dos balcãs e protegendo a área contra uma futura invasão persa.

As bases das reformas de Constantino foram mantidas pelos seus sucessores. A aliança com a Igreja, legítima herdeira de Cristo e do Império, tornou-se cada vez mais forte. Com isso, está formada uma das bases do pensamento político medieval - o Sumo pontífice, bispo de Roma, e as dinastias bárbaras / germânicas.

Lentamente, vai-se instalando nas vastas regiões imperiais um respeito ao imperador como governante supremo. Por este motivo, não podemos considerar completamente ineficazes os esforços das dinastias do Baixo Império para regularizar a transmissão de poder. A noção de Estado Patrimonial, presente na Dinastia Constantiniana, também estará presente na Dinastia Merovíngia de Clóvis, uma herança que os reis medievais vão aproveitar muito bem para legitimar e consolidar seus reinos.

\section{The Politics from Constantine and Formation Roman Empire}

Abstract: The paper aims at studying the Rome History just before Constantine ruled the Empire, considering that Constantine is considered as a direct heir of his four predecessors. Scholars are mostly interested in social and economic aspects, relegating to a secondary role the raw material and even the ideological concerns, so important ideologically. The numismatic collection stored at the National Historical Museum at Rio de Janeiro, Brazil, serves to show how images were used as propaganda for imperial rule.

Keywords: Coins. Empire. Ideology. Power. Symbol. 


\section{Notas}

${ }^{1}$ Agradeço aos colegas da UFRGS, em especial aos professores Anderson Z. Vargas e Francisco Marshall, pela oportunidade de trocarmos ideias. Agradeço ainda a Pedro Paulo Funari, Margarida Maria de Carvalho, Ciro Flamarion Cardoso, Maria Beatriz Florenzano, Vera Lúcia Tostes, Rejane Vieira, Eliane Rose Nery.

${ }^{2}$ Segundo Heródoto, junto com os venetti, era uma das tribos aliadas dos troianos. Com a derrota de Tróia, fugiram para o Leste Europeu. Os venetti foram para região do Vêneto, Norte da Itália.

${ }^{3}$ Usamos com referência o Codex Justinianus, lib. 13, it. 12, par. 2. CORPUS JURIS CIVILIS (CODEX) DN JUSTINIANI SACRATISS. Libri XII. Basilae (Suíça). Apud. Jo. Hervaeum, 1541, 890 páginas, do acervo da Biblioteca Nacional, Rio de Janeiro, Seção de Obras Raras.

${ }^{4}$ Todas as moedas aqui analisadas e interpretadas fazem parte da coleção do Museu Histórico Nacional. Apesar do acesso à Seção de Numismática e reserva técnica ser exclusivo aos funcionários e pesquisadores autorizados, encontra-se aberta para visitações a EXPOSIÇÃO PERMANENTE desde dezembro de 2002. Essa exposição relata toda a História das Sociedades, relação Moeda / História, desde a cunhagem da primeira moeda na Grécia (Lígia) até o euro atual.

${ }^{5}$ Muito comum às cunhagens do período vir, no anverso (famosa cara da moeda, reverso seria a coroa), o busto do imperador (no campo da moeda), acompanhado da legenda $P F A V G$ (pai, protetor Augusto) ou NOB C (nobilíssimo césar, título de todo o membro da família imperial). Por exemplo: CONSTANTINVS IVN NOB C ou DNCONSTANTINVS PF AVG.

${ }^{6}$ Segundo o numismata português Mario Gomes Marques, em seu livro Introdução à Numismática, as moedas e medalhas que melhor representam as construções romanas foram cunhadas por Constantino e seu filho Constâncio II.

\section{Referências Bibliográficas}

BASTIEN, Pierre. HUVELIN, Hélène. Trouvaille de Folles de la Période Constantienne (307-317). Belgique: Éditions Cultura Wetteren, 1969.

BRUUN, Patrick. Studies in Constantinian Numismatics. Papers from 1954 to 1988. Acta Instituti Romani Finlandiae. v. 12. Rome: Illus, 1991.

CALLY, Jean Pierre and BARRANDON, Jean Noel. L'Inflazione nel IV secolo (295361). Società romane e Impero tardoantico. v. I. Instituzioni, ceti, economie. Rome Bari: Editori Laterza, 1986. 
CARLAN, Cláudio Umpierre. As Fortificações e Constâncio II. In: Revista do Clube da Medalha. Ano XII, n. 24. Rio de Janeiro: Casa da Moeda do Brasil, 2003. . Moeda e poder em Roma, um mundo em transformação. Tese de Doutorado defendida na UNICAMP, dezembro de 2007.

CARVALHO, Margarida Maria de. Gregório de Nazianzo e a Polêmica em Torno da Restauração Pagã de Juliano. In: SILVA, Gilvan Ventura e MENDES, Norma Musco (Orgs.). Repensando o Império Romano. Perspectiva Socioeconômica, Política e Cultural. Rio de Janeiro: Mauad Editora, 2006.

CHARTIER, Roger. A História Cultural: entre práticas e representações. Tradução de Maria Manuela Galhardo. Lisboa: DIFEL, 1990.

DEPEYROT, G. Economie et Numismatique (284-491). Paris: Errance, 1987.

EUSEBIUS PAMPHILI, Bispo de Cesaréa. De Vita Constantini. v. 7. Lib. I. Leipzig: Texto da Edição I. A. Heikel, 1902.

FUNARI, Pedro Paulo Abreu e CARLAN, Cláudio Umpierre. Arqueologia Clássica e Numismática. Coleção Textos Didáticos, n. 62. Campinas: IFCH / UNICAMP, 2007.

FUNARI, Pedro Paulo Abreu. Grécia e Roma: vida pública e vida privada. Cultura, pensamento e mitologia, amor e sexualidade. 2. ed. São Paulo: Contexto, 2002.

FLORENZANO, Maria Beatriz Borba. O “Outro lado da moeda na Grécia Antiga”. In: Livro do Seminário Internacional O Outro Lado da Moeda. Rio de Janeiro: Museu Histórico Nacional. 2002.

LACTÂNCIO. De Mortibus Persecutorum. Paris: Ed. J. Moreau, 1954.

MARSHALL, Francisco. Ícone, Ideologia e Cultura. Ijuí: Leitura em Revista, 2003.

MARQUES, Mario Gomes. Introdução à Numismática. 1. ed. Lisboa: Publicações D. Quixote, 1982.

MOMIGLIANO, Arnaldo. Ensayos de Historiografia Antigua y Moderna. México: FCE, 1993.

NIETO SORIA, Jose Manuel. Ceremonias de La Realeza. Propaganda y Legitimacion en La Castilla Trastámara. Madrid: Editorial Nerea, 1993.

SEAR, David R. Roman Coins ande Their Values. 4th Revised Edition. London: Seaby Publications Ltd, 1988, p. 327.

ZÓSIME. Histoire Nouvelle. III. 18. éd. Paris: F. Paschoud, 1979. 


\section{Fontes Documentais}

\section{Fontes Numismáticas}

Moedas do Imperador Constantino I, o grande. Acervo do Museu Histórico Nacional, Rio de Janeiro, Medalheiro 3, gaveta 19, lâmina 3, fotografadas em março de 2005.

\section{Catálogos}

CATÁLOGO LOS AVREOS ROMANOS 196 A.C - 335 D.C. Por Xavier Calico, miembro de La Internacional Associatión of Professional Numismatics. Barcelona, 2002, p. 321.

MUSEU NACIONALD'ARTE DE CATALUNYA. Guia del Gabinet Numismàtic de Catalunya. Dirigida por Marta Campo. Barcelona: MNAC, 2007.

THE ROMAN IMPERIAL COINAGE. Edited by Harold Mattingly, C.H.V. Sutherland, R.A.G. Carson. V. VIII. London : Spink and Sons Ltda, 1983. 